Martin Frkan - Radomila Konecna - Gianni Nicoletto*

\title{
INFLUENCE OF THE HEAT TREATMENT ON THE MICROSTRUCTURE, MECHANICAL PROPERTIES AND FATIGUE BEHAVIOR OF ADDITIVELY MANUFACTURED TI6AL4V ALLOY
}

This contribution deals with the selective laser melting (SLM), which is one of the additive manufacturing (AM) technologies enabling the production of complex parts from metal powder, layer-by-layer wise. This technology uses laser as source of energy to melt a powder to compact state. Properties of final products can be significantly influenced by the process parameters and post-fabricated heat treatments. The purpose of this study is to determine the effect of a heat treatment on properties of the Ti6Al4V alloy specimens manufactured by Eosint M280 machine by the SLM. Three sets of specimens, treated at different temperatures $\left(730{ }^{\circ} \mathrm{C}, 900{ }^{\circ} \mathrm{C}, 1200{ }^{\circ} \mathrm{C}\right)$, resulting in a different structure, associated mechanical and fatigue properties, were investigated.

Keywords: SLM, Ti6Al4V, heat treatments, fatigue, microstructure

\section{Introduction}

Nowadays, the most widely used technology for metal powder additive manufacturing is the selective laser melting (SLM) that allows production of the near-net shape parts not producible by conventional procedures. This technology is considered to be one of the upcoming techniques to manufacture very complex components for industry like aerospace, automobile, biomedical, prototyping and other. Production of components of complex shapes is possible due to the layer-by-layer building approach. In this process, the $3 \mathrm{D}$ digital model is imported to the SLM operating software and it is sliced into two-dimensional layers, each one corresponding to a slice of the model. Layers are scanned with a laser beam according to the shape defined by the SLM software. The energy of the laser beam melts the powder to near-full density. This technology offers several advantages compared to conventional production, thanks to low material waste and high production flexibility that allows an extraordinary freedom regarding the part geometry [1], [2], [3].

Actual developments of fiber optics and high-power laser have enabled the SLM to process different metallic materials, such as aluminum, nickel, titanium alloys and steels. Similarly, this has also opened research opportunities for the SLM of ceramic and composite materials. A review is given in [2]. However, manufacturing of functional parts by the SLM process, requires extensive research of optimum process parameters to obtain fully dense metal components with good mechanical properties. Influence of these parameters is discussed in [4], [5], [6]

The Ti6A14V alloy is an established SLM material received by aerospace and biomedical industries for a good balance of strength, ductility, fracture toughness, creep characteristics, weldability and very good corrosion resistance [7]. This study investigates influence of the heat treatments on the basic mechanical properties, structure and on fatigue properties, as well.

Microstructure of the Ti6Al4V prepared by the SLM is a result of very high cooling rate during the crystallization $\left(10^{6} \mathrm{~K} / \mathrm{s}\right)$ and it is formed by an acicular $\alpha^{\prime}$ hexagonal martensitic phase. The formation and decomposition of $\alpha^{\prime}$ martensite in additively manufactured Ti6Al4V was studied in [8]. Due to the high cooling rate residual stresses arise, which affect the mechanical behavior of parts [9], [10]. To minimize the influence of residual stresses, parts are heat treated by the stress relieving heat treatment before separation from the substrate. Optimization of mechanical properties via the heat treatment of parts produced by the SLM is discussed in [11].

\section{Material and methods}

Specimens manufactured from titanium alloy Ti6A14V powder, supplied by EOS GmbH, were used. The powder particles are spherical, predominantly with a diameter range 25 to $45 \mu \mathrm{m}$ with chemical composition given in Table 1.

The specimens were manufactured by the SLM on EOS M280 machine. This system uses $\mathrm{Yb}$ fiber laser unit with a wavelength of $1075 \mathrm{~nm}$, which is able to supply the laser power of $200 \mathrm{~W}$ or $400 \mathrm{~W}$. The EOS M280 machine is equipped with building chamber filled by argon gas to avoid oxidation of titanium powder. A $400 \mathrm{~W}$ laser power, with a process chamber temperature of $80{ }^{\circ} \mathrm{C}$ and $60 \mu \mathrm{m}$ layer thickness, was used in the manufacturing process of the specimens. The scan strategy was based on a shell and core concept, where the internal part of the layer is first melted by raster laser motion then the contour of the layer is melted. The scanning of a successive layer is performed after rotation of the

\footnotetext{
* ${ }^{1}$ Martin Frkan, ${ }^{1}$ Radomila Konecna, ${ }^{2}$ Gianni Nicoletto

${ }^{1}$ Department of Materials Engineering, Faculty of Mechanical Engineering, University of Zilina, Slovakia

${ }^{2}$ Department of Engineering and Architecture, University of Parma, Italy

E-mail: Martin.Frkan@fstroj.uniza.sk
} 
Table 1 Chemical composition of the Ti6Al4V powder

\begin{tabular}{cccccccccc}
\hline & $\mathrm{Al}$ & $\mathrm{V}$ & $\mathrm{O}$ & $\mathrm{N}$ & $\mathrm{H}$ & $\mathrm{Fe}$ & $\mathrm{C}$ & $\mathrm{Ti}$ \\
\hline [wt. \%] & 6.08 & 3.9 & 0.085 & 0.005 & 0.002 & 0.25 & 0.007 & Bal. \\
\hline
\end{tabular}

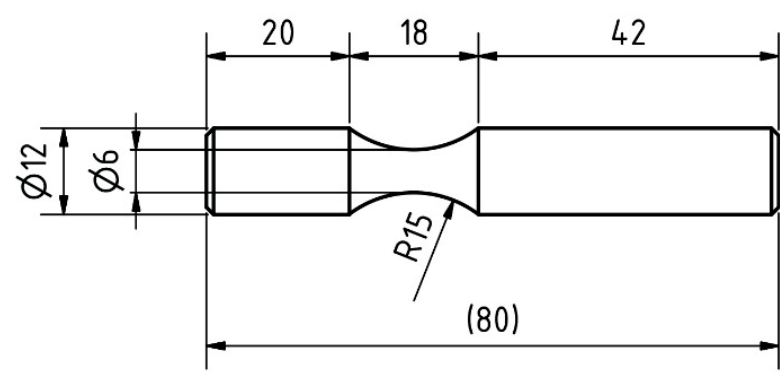

Figure 1 Rotating bending smooth specimens

scanning pattern for a 30-deg angle. All the specimens were built with their long axes parallel to the build direction (i.e. Z-axis).

Microstructure of specimens was observed using a light optical microscope Zeiss Axio Observer Z1M on polished and etched $(10 \% \mathrm{HF}$ for $10 \mathrm{~s})$ specimens that were cut from broken fatigue testing samples. The metallographic specimens have been prepared by the standard procedure of metallographic preparation for the Ti alloys. Observation of structure was made in order to characterize the material anisotropy, which arises due to the typical process conditions, (i.e. layer by layer generative principle, short interactions, high temperature gradients and the high localization of this manufacturing process).

Tensile tests were carried out on specimens fabricated in horizontal orientations (C orientation) on servo-hydraulic MTS 810 machine according to the ASTM 8/E 8M-08 standard at the company BEAM-IT [12].

Vickers hardness tests were performed on metallographically prepared specimens in polished state using HPO 250/AQ machine with a load of $10 \mathrm{~N}$ and $10 \mathrm{~s}$ of loading time. The average hardness was calculated from 10 measurements.

Fatigue testing was performed at room temperature on a rotating bending fatigue testing machine at the University of Parma [12]. A loading cycle was sinusoidal with a frequency $\mathrm{f}=50 \mathrm{~Hz}$. A fully reversal load was applied with the loading cycle asymmetry $\mathrm{R}=-1$ for all the tests. The shape and dimensions of fatigue specimens are shown in Figure 1. The diameter of the minimum cross-section is $6.0 \mathrm{~mm}$. The specimens were tested in as-built state. The tests were run up to failure or they were interrupted at $1 \times 10^{7}$ cycles (run-outs). The experimental data were plotted in terms of the S-N diagram, i.e. the number of cycles to failure, $\mathrm{N}$, in dependence on the stress amplitude $\sigma_{\mathrm{a}}$.

Heat treatment. During the SLM process considerable thermal-related internal stresses develop in the parts. For this reason the suitable stress relieving heat treatment is an important step in production of parts by the SLM. To investigate the effect of subsequent heat treatment on the microstructure, mechanical properties and fatigue life, three different heat treatments were performed on the Ti6-Al-4V SLM fatigue specimens. To protect against the oxidization of the surface, heat treatment was undertaken in a vacuum furnace, (TAV Vacuum Furnaces). The heat treatment (Figure 2) consists of heating to a maximum

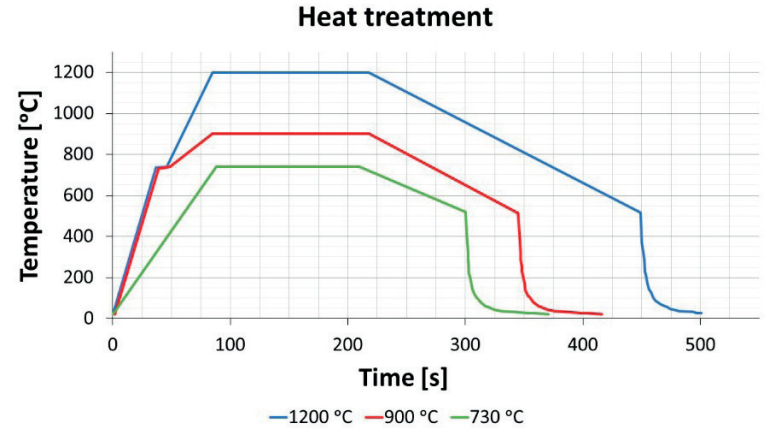

Figure 2 Graph of different heat treatments

temperature $\left(730{ }^{\circ} \mathrm{C}, 900{ }^{\circ} \mathrm{C}, 1200{ }^{\circ} \mathrm{C}\right)$, with soaking period of about 2 hours, followed by a control cooling to a temperature $520^{\circ} \mathrm{C}$. The last stage consists of fast cooling from a temperature $520{ }^{\circ} \mathrm{C}$ to a room temperature by argon gas, injected to a hot temperature chamber under pressure.

\section{Results and discussion}

\subsection{Structure}

Investigation of the microstructure of specimens prepared from the Ti6Al4V alloy powder by the SLM was aimed at the characterization of the microstructure depending on the temperature of the heat treatment. In cases of specimens heat treated at $730{ }^{\circ} \mathrm{C}$ and $900{ }^{\circ} \mathrm{C}$, the macrostructure of specimens show characteristic texture (Figure 3a and Figure 4a), which is similar for the lateral planes and differs from orthogonal planes. In Figure $3 \mathrm{a}$ are typical dark hot spots corresponding to the thermal history of the SLM production. During the material processing, the primary $\beta$-phase grains grow parallel to the build direction as a consequence of the thermal history experienced by the layer-wise fabrication. They are much longer than the layer thickness, which makes of about $60 \mu \mathrm{m}$. The microstructure of orthogonal planes shows a cross-section of the primary $\beta$ columnar grains, which are observed as polyhedral grains. The size of these grains corresponds to the width of the primary $\beta$ columnar grains. In the case of specimens heat treated at $1200{ }^{\circ} \mathrm{C}$, the structure (Figure $5 \mathrm{a}$ ) does not show the typical texture for the SLM technologies. The structure is the same for the lateral and orthogonal planes, characterized by large polyhedral grains because of the high temperature of the heat treatment.

The specimens heat treated at $730{ }^{\circ} \mathrm{C}$ show a detailed microstructure characterized by a fine needless of $\alpha^{\prime} / \alpha$-phase in $\beta$ matrix (Figure $3 b$ ). Black spots, generated by the local intense laser energy distribution, were locally observed as darker places. These localities are characterized by a finer microstructure. The average hardness for this microstructure is $392 \mathrm{HV} 10$.

Microstructure of specimens heat treated at $900{ }^{\circ} \mathrm{C}$ (Figure $4 \mathrm{~b}$ ) is characterized by the coarse needles of the $\alpha$-phase in the $\beta$ matrix, arranged in the Widmanstätten form. The thickness of the 

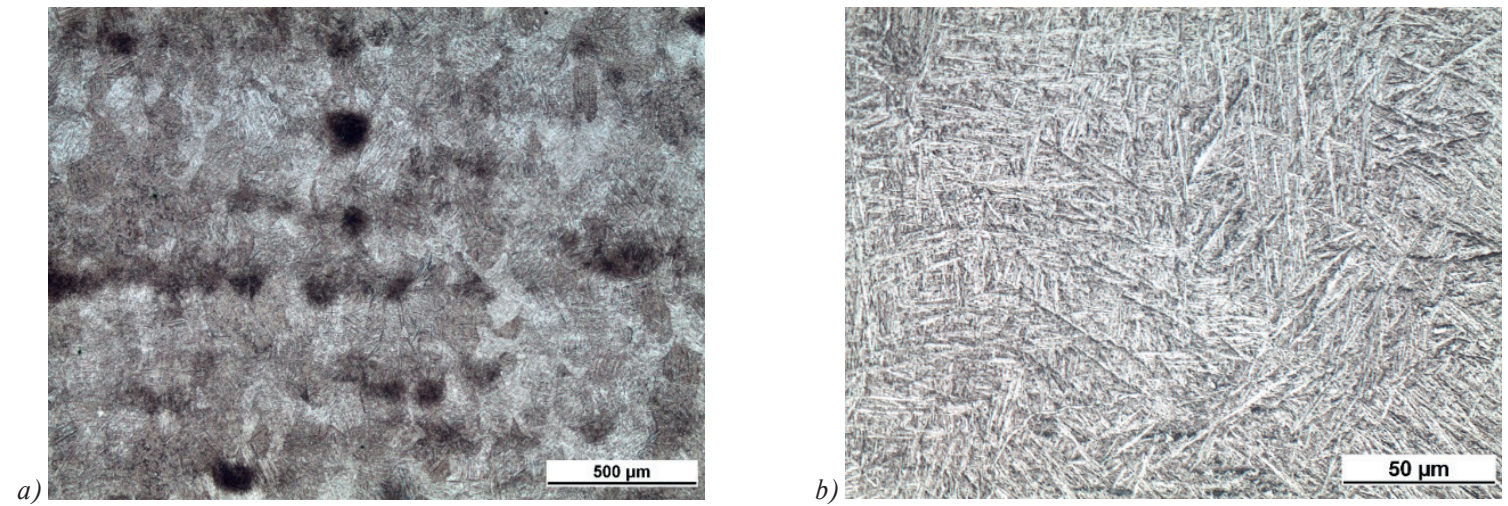

Figure 3 Ti6Al4V HT $730{ }^{\circ} \mathrm{C}$ a) columnar grains, b) acicular microstructure, etchant $10 \% \mathrm{HF}$
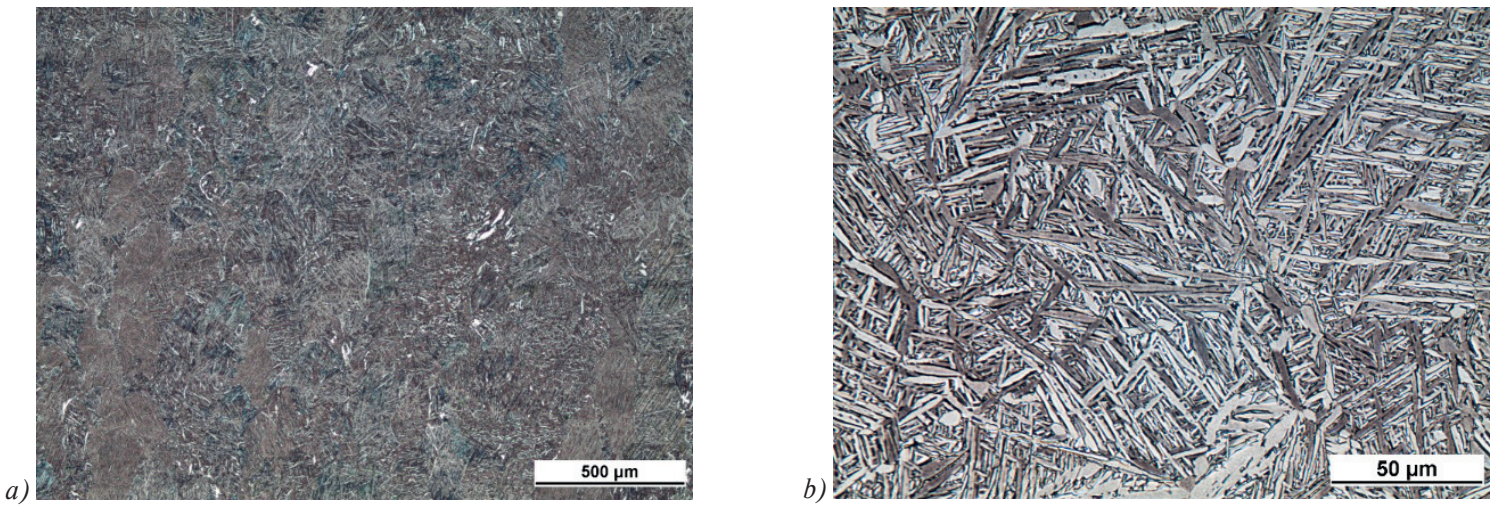

Figure 4 Ti6Al4V HT $900{ }^{\circ} \mathrm{C}$ a) columnar grains, b) coarse needles, etchant 10\% HF
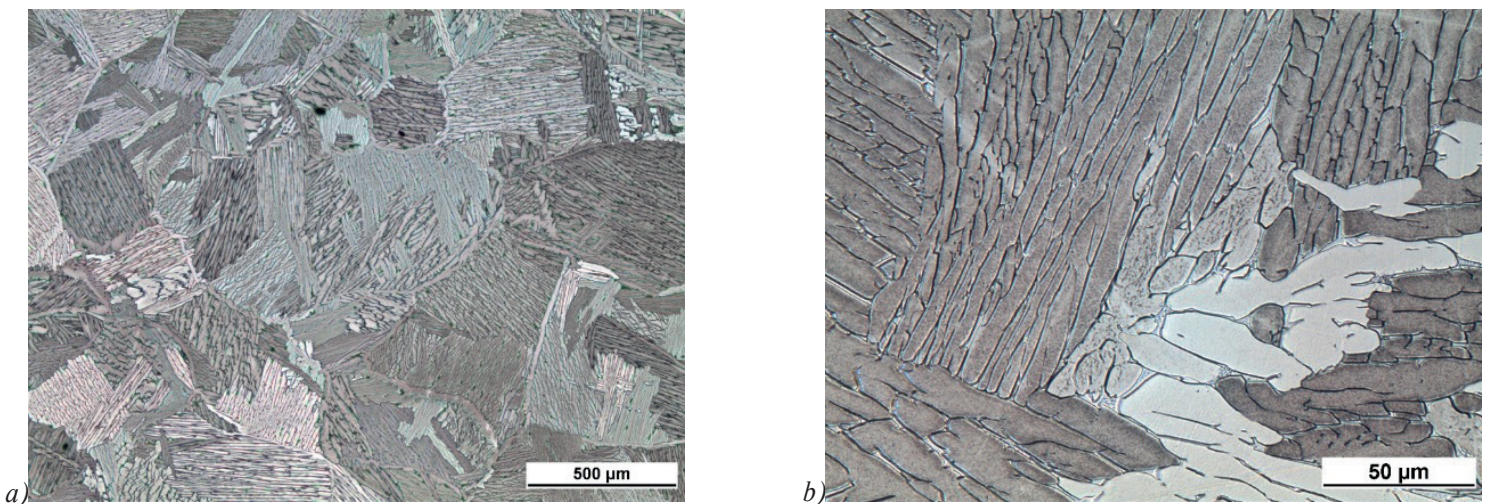

Figure 5 Ti6Al4V HT $1200{ }^{\circ} \mathrm{C}$, a) polyhedral grains, b) coarse lamellas of $\alpha+\beta$ phase, etch. $10 \% \mathrm{HF}$

$\alpha$-needles is different and it depended on the orientation of the lamellas to the metallographic cross section. Due to a different stress relieving temperature, they showed homogeneous structure without black spots compared to the heat treated specimens at $730{ }^{\circ} \mathrm{C}$. The average hardness is corresponding to the coarser structure and is $347 \mathrm{HV} 10$.

The microstructure of specimens heat treated at $1200{ }^{\circ} \mathrm{C}$ is characterized by the coarse lamellas of the $\alpha+\beta$ phase (Figure $5 b$ ). The polyhedral grains show colonies of lamellas with the same orientation. Grain growth occurred due to the high temperature $1200{ }^{\circ} \mathrm{C}\left(\beta\right.$ transus is $995^{\circ} \mathrm{C}$ ), when $\alpha^{\prime}$-martensite (as-fabricated structure) is completely replaced by grains of the $\beta$-phase. These large grains of the $\beta$-phase transform to coarse lamellas of the $\alpha+\beta$ phase during the cooling. The average hardness for this structure is the lowest (315 HV 10) due to the high content of $\beta$-phase.

\subsection{Tensile tests}

The tensile tests were carried out on specimens in as-built state, fabricated in horizontal orientations (axis of specimens coincides with axis of the building direction) by the BEAM-IT [12]. The average room-temperature mechanical properties of the Ti6Al4V alloy under different conditions are given in Table 2. The yield strength, ultimate tensile strength and percentage strain were obtained as direct output from the tensile testing machine. The tensile properties (ultimate tensile strength, yield strength) are comparable to the standard Ti6Al4V annealed material [13]. Specimens heat treated at $730{ }^{\circ} \mathrm{C}$ have comparable tensile properties as standard solution treated and aged material. Specimens heat treated at $900{ }^{\circ} \mathrm{C}$ have comparable tensile properties as duplex annealed material. The lowest tensile 
Table 2 Material condition and mechanical properties

\begin{tabular}{cccc}
\hline Condition & Yield strength & Ultimate tensile strength & Elongation \\
$\%$
\end{tabular}

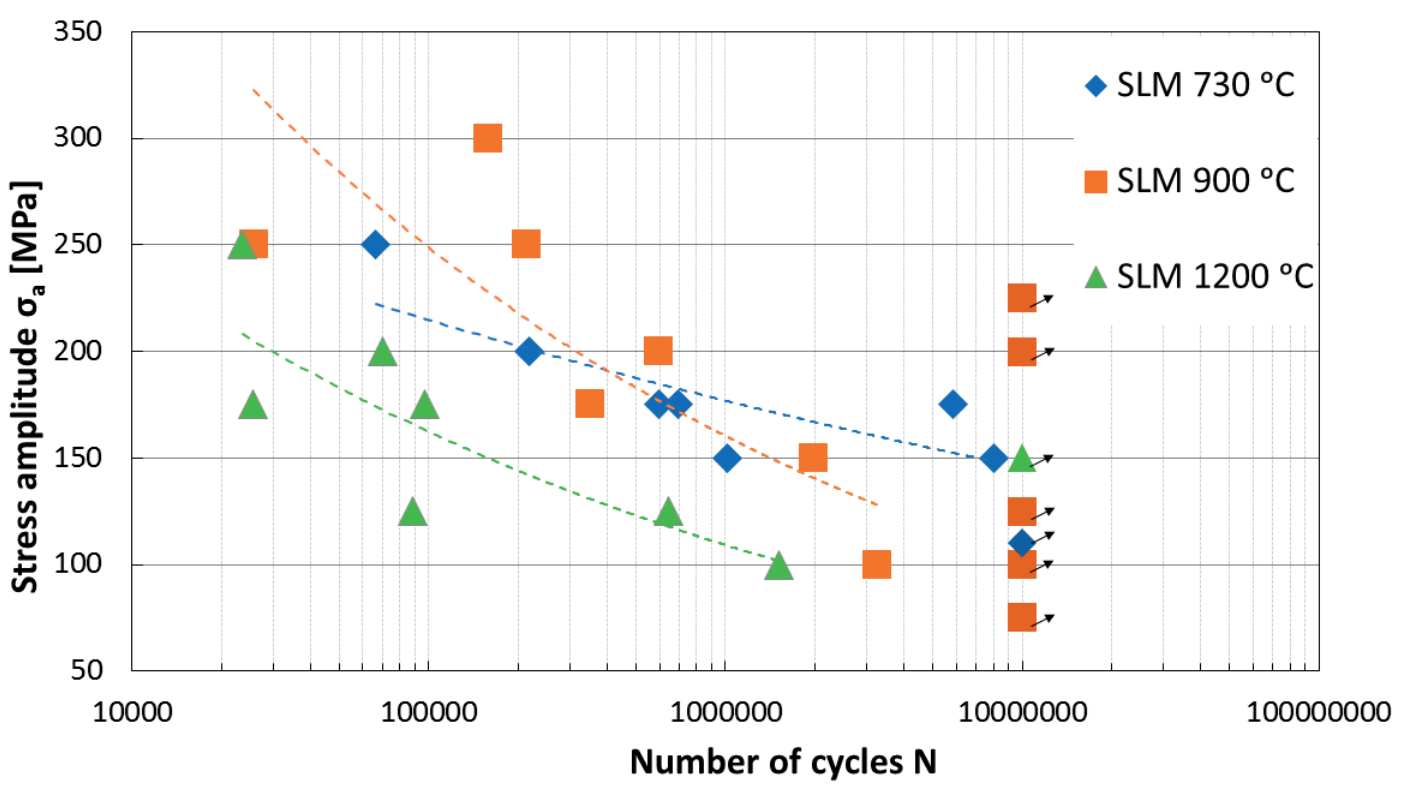

Figure 6 Influence of the heat treatment on S-N curves of as-built DMLS Ti6Al4V

properties have specimens heat treated at $1200{ }^{\circ} \mathrm{C}$, which was also reflected to the fatigue behavior. From comparison of the SLM specimens, it can be said, that finer structure is resulting in the higher yield and ultimate tensile strengths. Relationship between the structure and elongation is not clearly defined. Elongation was the highest for specimen heat treated at $900{ }^{\circ} \mathrm{C}$.

\subsection{Fatigue}

Results of the fatigue tests are shown as S-N curves (Figure 6) [12]. All specimens had the same orientation with respect to the build direction. Their surfaces were left in the as-built state after heat treatment. The structure, which also affects the fatigue lifetime [14], is similar for temperatures 730 and $900{ }^{\circ} \mathrm{C}$, however, for specimens heat treated at $1200{ }^{\circ} \mathrm{C}$ it different (see microstructures). The different heat treatments therefore affect the fatigue behavior. From the fatigue data of Figure. 6 it can be stated that specimens heat treated at $730^{\circ} \mathrm{C}$ and $900^{\circ} \mathrm{C}$ show similar fatigue behavior in terms of the regression curves. On the other hand, fatigue data of specimens heat treated at $730{ }^{\circ} \mathrm{C}$ exhibit smaller scatter, probably due to the finer microstructure. The worst fatigue behavior is for the specimens that were heat treated at $1200{ }^{\circ} \mathrm{C}$ due to the coarse lamellar structure. The influence of lamellar thickness on the fatigue behavior have been investigated in [13], where it was found that the fatigue behavior is strongly affected by the width of the alpha lamellae in fully lamellar microstructures.

Although the structure is different (thickness of $\alpha$-phase lamellas, primary $\beta$ grain size, texture), differences in the fatigue life are small. The fatigue strength at $1 \times 10^{7}$ can be estimated as less than $150 \mathrm{MPa}$. This low fatigue strength is caused by the rough surface, which significantly affects the fatigue strength, due to the high fatigue notch sensitivity of Ti-alloys [15], [16].

The specimens in as-built state produced by the SLM technology have a rough surface [17], caused by un-melted particles and layer-by-layer manufacturing method used by additive manufacturing technology.

The role of the surface quality on fatigue life is discussed based on Figure 7, where data published by Janecek et al. [18], of Ti6Al4V alloy specimens tested in rotating bending $(\mathrm{R}=-1)$ in the range from $10^{4}$ to $10^{7}$ cycles at the testing frequency of $30 \mathrm{~Hz}$ are presented. Janecek et al. tested specimens, electropolished in their gage section, compared to the present as-built SLM specimens. The fatigue strength at $10^{7}$ cycles is rather high, about $400 \mathrm{MPa}$, for Janecek et al. This result is confirmed by previously published rotating bending test results obtained with SLM Ti6Al4V specimens having machined surfaces and heat treated similarly to the present case (i.e. maximum temperature $740{ }^{\circ} \mathrm{C}$ instead of $730{ }^{\circ} \mathrm{C}$ ) [19]. 


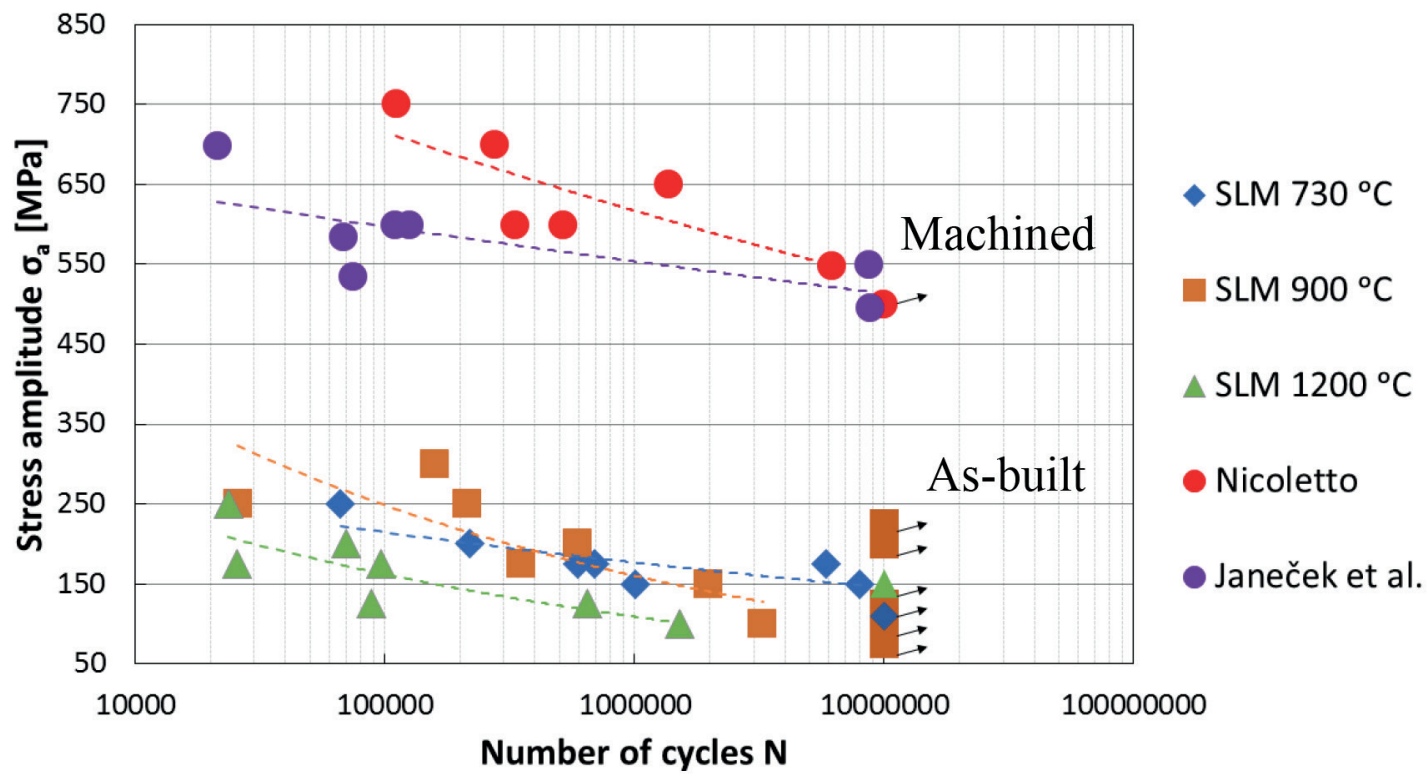

Figure 7 S-N curves for as-built and machined DMLS Ti6Al4V

In the case of Janecek et al. [18], the material was subjected to the following heat treatment: annealing at $980{ }^{\circ} \mathrm{C}$ for $1 \mathrm{~h}$, followed by water quenching; annealed at $800{ }^{\circ} \mathrm{C}$ for $1 \mathrm{~h}$ followed by air cooling; final aging at $500{ }^{\circ} \mathrm{C}$ for $24 \mathrm{~h}$. It resulted in a bi-modal microstructure, with ultimate tensile strength of $1050 \mathrm{MPa}$ and yield strength of $950 \mathrm{MPa}$. Generally, the bi-modal microstructure guarantees good fatigue endurance of the Ti6Al4V alloy. On the other hand, the present material, heat treated at $730^{\circ} \mathrm{C}$ reached even higher fatigue strength.

The data by Janecek et al. [18] and Nicoletto [19] demonstrate that the specimens manufactured by the SLM technology and machined surfaces have higher fatigue strength compared to the conventional alloy tested by Janecek et al. [18]. The difference in the fatigue life is especially visible in the low-cycle fatigue region, where the higher load amplitudes are used. This increase in fatigue life is probably due to the very fine microstructure of specimens produced by the SLM method.

\section{Conclusion}

The aim of this study was to discuss the influence of the heat treatment temperature on the microstructure, mechanical properties and fatigue behavior of the Ti6Al4V alloy produced by the SLM technology. This study leads to the following conclusions:
- The microstructure of the Ti6Al4V specimens prepared by the SLM and then heat treated is characterized by primary $\beta$ columnar grains that are filled with fine needles of $\alpha^{\prime} / \alpha$-phase in the case of the heat treatment at $730{ }^{\circ} \mathrm{C}$ or the coarse needles of the $\alpha$ phase in the $\beta$ matrix in the case of the heat treatment $900{ }^{\circ} \mathrm{C}$ or coarse lamellas of the $\alpha+\beta$ at $1200{ }^{\circ} \mathrm{C}$.

- The mechanical properties, obtained from the tensile test for Ti6Al4V alloys produced by the SLM technology and subsequently heat treated, are comparable to mechanical properties of the wrought Ti6Al4V.

- For the best heat treatment, the fatigue strength at $1 \times 10^{7}$ for as-built Ti6Al4V was estimated at $150 \mathrm{MPa}$. In the case of machined surfaces, the fatigue strength at $1 \times 10^{7}$ was estimated to be $500 \mathrm{MPa}$, similar to what is reported for the wrought Ti6Al4V. The surface quality has therefore a fundamental role in the future application of the SLM technology.

\section{Acknowledgment}

The research was supported by the Slovak VEGA grant No. $1 / 0685 / 2015$. Cooperation with Beam-It, Fornovo Taro (Italy) is gratefully acknowledged.

\section{References}

[1] GIBSON, I., ROSEN, D., STUCKER, B.: Additive Manufacturing Technologies: 3D Printing, Rapid Prototyping and Direct Digital Manufacturing. Springer, New York, p. 498, 2015.

[2] YAP, C. Y., CHUA, C. K., DONG, Z. L., LIU, Z. H., ZHANG, D. Q., LOH, L. E., SING, S. L.: Review of Selective Laser Melting: Materials and Applications. Applied Physics Reviews, 2(4), 041101, 2015. https://doi.org/10.1063/1.4935926 
[3] HORN, T. J., HARRYSSON, O. L. A.: Overview of Current Additive Manufacturing Technologies and Selected Applications. Science Progress, 95(3), 255-282, 2012. https://doi.org/10.3184/003685012X13420984463047

[4] SUN, J., YANG, Y., WANG, D.: Parametric Optimization of Selective Laser Melting for Forming Ti6Al4V Samples by Taguchi Method. Optics \& Laser Technology, 49, 118-124, 2013. https://doi.org/10.1016/j.optlastec.2012.12.002

[5] ZHANG, S., WEI, Q., CHENG, L., LI, S., SHI, Y.: Effects of Scan Line Spacing on Pore Characteristics and Mechanical Properties of Porous Ti6A14V Implants Fabricated by Selective Laser Melting. Materials \& Design, 63, 185-193, 2014. https://doi. org/10.1016/j.matdes.2014.05.021

[6] YADROITSEV, I., BERTRAND, P., SMUROV, I.: Parametric Analysis of the Selective Laser Melting Process. Applied Surface Science, 253(19), 8064-8069, 2007. https://doi.org/10.1016/j.apsusc.2007.02.088]

[7] WELSCH, G., BOYER, R., COLLINGS, E. W.: Materials Properties Handbook: Titanium Alloys. ASM International, p. 1176, 1994.

[8] XU, W., BRANDT, M., SUN, S., ELAMBASSERIL, J., LIU, Q., LATHAM, K., XIA, K., QIAN, M.: Additive Manufacturing of Strong and Ductile Ti-6Al-4V by Selective Laser Melting Via In Situ Martensite Decomposition. Acta Materialia, 85, 74-84, 2015. https://doi.org/10.1016/j.actamat.2014.11.028

[9] ROBERTS, I. A.: Investigation of Residual Stresses in the Laser Melting of Metal Powders in Additive Layer Manufacturing [online]. PhD. Thesis, University of Wolverhampton, 2012. Available: https://core.ac.uk/download/pdf/9559670.pdf.

[10] SHIOMI, M., OSAKADA, K., NAKAMURA, K., YAMASHITA, T., ABE, F.: Residual Stress within Metallic Model Made by Selective Laser Melting Process. CIRP Annals - Manufacturing technology, 53(1), 195-198, 2004. https://doi.org/10.1016/S00078506(07)60677-5

[11] VRANCKEN, B., THIJS, L., KRUTH, J. P., HUMBEECK, J. V.: Heat Treatment of Ti6Al4V Produced by Selective Laser Melting: Microstructure and Mechanical Properties. Journal of Alloys and Compounds, 541, 177-185, 2012. https://doi.org/10.1016/j. jallcom.2012.07.022

[12] NiCOletTo, G., MAISANO, S., ANTOLOTTI, M., DALL'AGLIO, F.: Influence of Post Fabrication Heat Treatments on the Fatigue Behavior of Ti-6al-4v Produced by Selective Laser Melting. Procedia Structural Integrity, 7, 133-140, 2017. https://doi. org/10.1016/j.prostr.2017.11.070

[13] DONACHIE, M. J.: Titanium: A Technical Guide, 2nd ed. ASM International, 2000.

[14] FRKAN, M., KONECNA, R., NICOLETTO, G.: Surface Quality and Fabrication Directionality Effects on the Fatigue Behavior of DMLS Ti6Al4V. Proceedings of 26th International Conference on Metallurgy and Materials (METAL 2017), Czech Republic, 1567-1572, 2017.

[15] KAHLIN, M., ANSELL, H., MOVERARE, J. J.: Fatigue Behaviour of Notched Additive Manufactured Ti6Al4V with As-Built Surfaces. International Journal of Fatigue, 101(P1), 51-60, 2017. https://doi.org/10.1016/j.ijfatigue.2017.04.009

[16] BOYER, H. E.: Atlas of Fatigue Curves. ASM International, p. 518, 1986.

[17] NICOLETTO, G., KONECNA, R., KUNZ. L., FRKAN. M.: Influence of As-Built Surface on Fatigue Strength and Notch Sensitivity of Ti6Al4V Alloy Produced by DMLS. MATEC Web of Conferences, 165, 02002, 2018. https://doi.org/10.1051/ matecconf/201816502002

[18] JANECEK. M., NOVY, F., HARCUBA, P., STRASKY, J., TRSKO, L., MHAEDE, M.: The Very High Cycle Fatigue Behavior of Ti-6al-4v Alloy. Acta Physica Polonica A, Proceedings of the International Symposium on Physics of Materials (ISPMA13), 128, 4, 2015. https://doi.org/10.12693/APhysPolA.128.497

[19] NICOLETTO, G.: Efficient Determination of Influence Factors in Fatigue of Additive Manufactured Metals. Procedia Structural Integrity, 8, 184-191, 2018. https://doi.org/10.1016/j.prostr.2017.12.020 